\title{
HISTÓRIA DO BRASIL PARA O ENSINO SECUNDÁRIO: legislação e programas (1889-1950)
}

HISTORY OF BRAZIL FOR HIGH SCHOOL: legislation and curriculum (18891950)

Kênia Hilda Moreira ${ }^{1}$

Resumo: Objetiva-se discutir sobre as legislações e programas para o ensino de História do Brasil, de nivel secundário, no contexto de 1889 , com a implantação da República, até 1950, quando termina a vigência da Lei Orgânica do Ensino secundário, de 1942. Parte-se da hipótese da divisão do periodo em duas conjunturas, entre 1889 e 1920 e 1920 a 1950. Como fonte, recorremos a Gasparello (2002), Resnik (1992) e Lacombe (1973), dentre outros. Na perspectiva da história das disciplinas e do ensino secundário (CHERVEL 1990, 1992, 1999), a presente investigação evidencia as idas e vindas da disciplina História do Brasil nos programas curriculares nacionais, em diálogo com as disciplinas de História Geral/Universal e História da América, bem como as relações de poder em disputa na elaboração e consolidação do currículo de História da Brasil.

Palavras-chave: Disciplina História do Brasil. Ensino Secundário. Políticas Educacionais.

Abstract: The aim is to discuss the laws and curriculum for the teaching of History of Brazil, for high school, in the context of 1889, with the implementation of the Republic, until 1950, when the Law "Lei Orgânica de Ensino Secundário", of 1942, expires. It starts from the hypothesis of the division of the period in two conjunctures, between 1889 and 1920 and 1920 to 1950. As a source, we use Gasparello (2002), Resnik (1992) and Lacombe (1973), among others. From the perspective of the History of the Disciplines and High School (CHERVEL 1990, 1992, 1999), the investigation evidences the comings and goings of the discipline History of Brazil in the national curricular programs, in dialogue with the disciplines of General / Universal History and History of America, as well as the power relations in dispute in the elaboration and consolidation of the curriculum of History of Brazil.

Key-words: Discipline History of Brazil. High school. Educational Policies.

\footnotetext{
${ }^{1}$ Professora de História da Educação, no Programa de Pós-Graduação em Educação e na Faculdade de Educação, da Universidade Federal da Grande Dourados. E-mail: keniahildamoreira@yahoo.com.br
} 


\section{Introdução}

Objetivamos discutir sobre o contexto sócio-politico-educacional nos quais foram estabelecidas politicas educacionais, especialmente para o nível secundário, e os programas específicos para o ensino de História do Brasil. O período eleito está delimitado entre 1889, quando se inicia o governo republicano, e 1950, último ano de vigência da Lei Orgânica do Ensino secundário, de 1942, e dos respectivos programas de ensino elaborados em âmbito federal pelo Ministério da Educação e Saúde Pública.

Para apresentar tal discussão dividimos o texto em duas partes: A primeira trata das conjunturas politicas e sociais que influenciaram a produção de programas e currículos para a disciplina História do Brasil, separadamente: 1889-1920 e 1920-1950. A segunda parte aprofunda-se nas discussões em torno dos programas e currículos elaborados entre 1889 e 1950 para a disciplina História do Brasil.

\section{Duas conjunturas politicas e culturais distintas}

Nesta primeira parte, enfatizamos a existência de duas conjunturas politicas e culturais distintas: 1889 a 1920 e 1920 a 1950, conforme Lorenzo e Costa (1997), para quem “as origens do Brasil moderno" estão na década de 1920: período de crise e renovação política. Sandes (2000), corroborando com tal afirmação expõe que a Primeira Guerra Mundial (1914-1918) e a Revolução Russa (1917) são simultaneamente sinais de crise da doutrina liberal e formação de um novo mundo.

\section{Primeira conjuntura: 1889 A 1920}

A partir da década de 1870, percebe-se acelerado crescimento do descontentamento com o regime monárquico, que não correspondia, dizia-se, às mudanças na estrutura socioeconômica, principalmente a partir das 
campanhas abolicionistas, do fim da mão-de-obra escrava e da tentativa de modernização capitalista. A esse descontentamento, associava-se os atritos da monarquia com o Exército, especialmente após a Guerra contra o Paraguai, e com a Igreja. Esses, dentre outros fatores, contribuíram para o surgimento de novos grupos sociais e políticos e à receptividade às ideias de reforma ${ }^{2}$. A partir do Manifesto Republicano surgiram partidos republicanos locais em São Paulo, Rio Grande do Sul, Pernambuco e Minas Gerais. O desfecho é conhecido, a crise da monarquia propiciou a implantação do regime republicano ${ }^{3}$.

No campo sociopolitico, o novo regime não alterou a situação dos clãs rurais e dos latifúndios, os quais estavam no cerne da politica dita "coronelista", por sua vez, base da estrutura do poder na Primeira República, isto é, a "política do café-com-leite".

No entanto, a abolição da escravatura e a introdução do trabalho livre propiciaram o desenvolvimento do modo capitalista de produção e de vida. Aos poucos, surgiu uma divisão social do trabalho, com as camadas médias e o proletariado industrial, além da diferenciação das classes dominantes com a consolidação do empresariado rural. Como pano de fundo, surgia o urbanismo. Em conjunto, tais fenômenos resultaram em mudanças de ideias, sentimentos e atitudes.

Os governantes e partidários do novo regime atuaram no sentido de legitimá-lo desde o "ponto de vista afetivo e moral" e "[...] conquistar os corações e mentes do povo brasileiro para o novo projeto político que se iniciava, lançando mão de símbolos concretos" (GOMES, 2002, p. 45). O desafio das sociedades ocidentais consistia, então, na consolidação dos Estados nacionais. Entre outros, utilizava-se bandeira, brasão, hino, festas, feriados e livros escolares como meios de criação da identidade nacional. Escolas, jornais, partidos politicos e igrejas, propagaram os simbolos republicanos valendo-se de rituais cívicos e processos pedagógicos. (OLIVEIRA, 2002).

\footnotetext{
2 Cf. Casalecchi (1987) e Gomes (2002).

${ }^{3}$ Cf. Carvalho $(1987,1990)$.
} 
No caso brasileiro, predominavam no ambiente intelectual as teorias cientificistas de Auguste Comte, Henry Buckle, Charles Darwin e Herbert Spencer, teorias que certamente conformaram a visão de mundo de gerações ${ }^{4}$. O clima cientificista repercutiu e fortaleceu o campo historiográfico e produziu estudos especializados e um círculo de historiadores de ofício relativamente distanciados do Instituto Histórico e Geográfico Brasileiro e mais próximos da Academia Brasileira de Letras ${ }^{5}$. Todavia, diversos autores de livros didáticos de História eram sócios do instituto.

Um historiador que se destaca nos anos iniciais da República no âmbito da escrita da História nacional é Capistrano de Abreu, com Capitulos de História colonial (1500 a 1800), publicado em 1907. O autor elabora uma releitura do Brasil contrapondo-se à interpretação de Varnhagen. Capistrano de Abreu enfatiza as dimensões sociais e econômicas e não apenas política, como defendem vários autores ${ }^{6}$.

Além desse autor, João Ribeiro, Oliveira Lima e Alcântara Machado, conforme Gomes (1999), refletiam sobre a nacionalidade e a identidade do país. Referenciavam-se em teóricos como Comte, Spencer, Taine e Martius e nas modernas influências historiográficas, francesa, alemã e portuguesa.

O oficio de historiador, na virada do século era exercido por uma gama abrangente de intelectuais, os "homens de letras", uma vez que não havia distinções disciplinares nítidas no Brasil até 1930.

Ao analisar os historiadores veiculados no suplemento "Autores e Livros" do jornal A Manhã e artigos da revista Cultura Politica, Gomes (1999) afirma que eram historiadores todos que produziram na área dos estudos históricos, havendo um esforço de distinção tanto da filosofia e literatura lato sensu, quanto dos estudos politico-sociais. Tal distinção não impedia que os autores acumulassem outras especialidades, sendo com frequência, poetas, romancistas, juristas ou jornalistas.

\footnotetext{
${ }^{4}$ Cf. Wehling (1994), Reis (1999) e Gasparello (2002).

5 Sobre a ABL e sua importância nos primeiros anos da República, Cf. Gomes (1999) e Gasparello (2002).

${ }^{6}$ Dentre eles: Rodrigues (1965 e 2000), Reis (1999), Vianna (1999), Arruda \& Tengarrinha (1999) e Gomes (1999).
} 
Quanto ao sistema de educação escolar instaurado com a República, é necessário considerar que a ampliação da escolarização aconteceu de forma gradual e variou de acordo com cada Estado da Federação. Assim como hoje, a diversidade regional interferia na composição política e administrava das unidades federativas. A maioria dos estados se encontrava em situação econômica desfavorável, com exceção de São Paulo, Minas Gerais, Rio Grande do Sul e Distrito Federal, conforme demostra a tabela a seguir.

\begin{tabular}{|c|c|c|c|c|c|}
\hline & $\begin{array}{l}\text { Escolas } \\
\text { Estaduais }\end{array}$ & $\begin{array}{c}\text { Escolas } \\
\text { Municipais }\end{array}$ & $\begin{array}{c}\text { Escolas } \\
\text { Particulares }\end{array}$ & $\begin{array}{c}\text { Conclusão } \\
\text { Curso } \\
\text { Primário }\end{array}$ & $\begin{array}{c}\text { Conclusão } \\
\text { Curso } \\
\text { Secundário }\end{array}$ \\
\hline São Paulo & 1248 & 363 & 329 & 2931 & 299 \\
\hline Rio G. do Sul & 1037 & 158 & 236 & 2459 & 125 \\
\hline Minas Gerais & 1379 & 486 & 382 & 2168 & 140 \\
\hline $\begin{array}{ll}\text { Rio } & \text { de } \\
\text { Janeiro } & \end{array}$ & & 302 & 136 & 1814 & 500 \\
\hline Alagoas & 223 & 16 & 51 & 1633 & 63 \\
\hline Bahia & 597 & 228 & 235 & 1585 & 155 \\
\hline $\begin{array}{l}\text { Santa } \\
\text { Catarina }\end{array}$ & 161 & 106 & 267 & 1517 & 71 \\
\hline Pernambuco & 136 & 377 & 125 & 1145 & 207 \\
\hline $\begin{array}{ll}\text { Rio } & \text { de } \\
\text { Janeiro } & \\
\end{array}$ & 389 & 45 & 106 & 816 & 20 \\
\hline Amazonas & 215 & 12 & 36 & 774 & 48 \\
\hline Pará & 137 & 196 & 86 & 766 & 36 \\
\hline Paraná & 240 & 14 & 78 & 561 & 12 \\
\hline Ceará & 315 & 22 & 129 & 546 & 88 \\
\hline Piauí & 101 & 13 & 79 & 485 & 20 \\
\hline Paraíba & 79 & 66 & 81 & 418 & 19 \\
\hline $\begin{array}{l}\text { Espírito } \\
\text { Santo }\end{array}$ & 101 & 62 & 52 & 333 & \\
\hline Mato Grosso & & 85 & 34 & 274 & 14 \\
\hline Maranhão & 140 & 52 & 51 & 239 & 1 \\
\hline Goiás & 68 & 51 & 47 & 237 & 22 \\
\hline $\begin{array}{l}\text { Rio G. do } \\
\text { Norte }\end{array}$ & 68 & 52 & 54 & 168 & 12 \\
\hline
\end{tabular}

A tabela demonstra ainda o nivel de expansão do ensino primário no governo republicano, enquanto o ensino secundário continuava destinado à formação da elite do país.

Entre 1907 e 1920 houve um crescimento de mais de 100\%. 
Tabela 2 - População e educação no Brasil (1888 a 1920)

\begin{tabular}{c|c|c|c|c|c}
\hline \multicolumn{2}{c|}{ População (em milhões) } & \multicolumn{3}{c}{ Matricula escolar } \\
\hline Ano & Total & Alfabetizados & Primário & Secundário & Universitário \\
\hline 1888 & 13,67 & & 258302 & & \\
\hline 1890 & 14,33 & 2,12 & & & \\
\hline 1895 & 15,96 & & & & \\
\hline 1900 & 17,32 & 4,45 & & & \\
\hline 1905 & 20,00 & & & & 5792 \\
\hline 1907 & 20,86 & & 638378 & 20000 & 8285 \\
\hline 1910 & 23,17 & & & & 10000 \\
\hline 1915 & 24,67 & & & & \\
\hline 1920 & 30,64 & 7,49 & 1250729 & 50000 & \\
\hline
\end{tabular}

Fonte: Hallewell (2005, p. 249).

No entanto, esse crescimento ainda era insuficiente quando relacionado com o total geral da população. De acordo com o Censo Geral de 1920, a maioria de jovens em idade de cursar o secundário estava fora da escola. Havia cerca de seis milhões de jovens de ambos os sexos, entre 12 e 20 anos, entretanto, nem 1\% estavam matriculados. (NAGLE, 1976).

Mesmo com o advento da República, o ensino secundário tardou a ser redefinido, e continuou a enfatizar os estudos de humanidades necessários ao ingresso nos cursos superiores ${ }^{7}$.

No período colonial o "ensino secundário" tomou as formas religiosas quando ministrado em seminários, e forma laica quando em "aulas avulsas". No Império o ensino secundário normatizado pelo governo central era ministrado em colégios, liceus e ateneus. A partir de 1837, o Colégio Pedro II assumiu o status de instituição modelar para as demais instituições existentes na Corte e nas províncias. Os colégios e liceus correspondiam à transição da escola régia preconizada pelos iluministas portugueses para os ginásios organizados com currículos seriados e sequenciais.

Nas décadas iniciais da República, o ensino secundário vigente resultou de um processo de institucionalização marcado pelo embate com o sistema de exames parcelados, então, como se sabe, para ingressar nos cursos superiores bastava a aprovação nos exames preparatórios. Para Haidar (2008, p. 12), os esforços visando a conferir organicidade do ensino público secundário durante

\footnotetext{
7 Sobre o ensino secundário, sua natureza e finalidades Cf. Chervel e Compère (1999); sobre o ensino secundário no Brasil, sua natureza e finalidades Cf. Gasparello (2002).
} 
o Império foram em boa parte frustrados devido a "influência desagregadora dos exames parcelados e preparatórios".

De um lado, criado para atender as classes dirigentes, o secundário era reservado aos jovens do sexo masculino e possuía uma natureza elitista; de outro, a escassez de estabelecimentos definia o caráter seletivo do secundário. Os padrões econômico-sociais, pedagógicos e político-administrativos que compõem a base dessa modalidade de ensino, lhe conferem caráter propedêutico. Para Nagle (1976, p. 147), no período de 1890 a 1920 os planos de estudos “[...] prestigiam tão-somente as disciplinas tradicionais (línguas, matemáticas, ciências, conhecimentos de Geografia e História), com predominância dos estudos literários sobre os estudos científicos".

Os questionamentos referiam-se ao caráter propedêutico e humanista. Escreve Nagle (1976, p. 148): “A articulação entre o ensino secundário e o superior são decisivos na definição do caráter seletivo e preparatório do ensino secundário”. Para Gasparello “[...] a busca na definição da 'identidade’ do secundário surgiu recorrente desde meados do século XIX até a Primeira República, em debates parlamentares e educacionais, que o associavam aceitando ou criticando - ao estudo das humanidades clássicas" 8 (GASPARELLO, 2002, p. 64, grifo da autora).

Tais afirmações nos permitem reconhecer que, as legislações sobre o ensino secundário no contexto investigado evidenciaram disputas, por um lado, ao definir-se ora como ensino preparatório ora como formativo, por outro, ao enfatizar ora o ensino humanista, ora o científico.

Por exemplo, a reforma do ensino proposta por Benjamin Constant em 1890, então ministro da Instrução Pública, Correios e Telégrafos, e implantada antes da promulgação da Constituição de 1891, em conformidade com o pensamento positivista, favoreceu a pedagogia realista, isto é, o conhecimento das coisas e das ciências, em contraposição à pedagogia humanista considerada afastada da realidade ${ }^{9}$. Os programas de ensino implantados em 1892, 1893, 1895 e 1898 e formulados pelos catedráticos do Colégio Pedro II

\footnotetext{
${ }^{8}$ Sobre o confronto entre o ensino humanista e o científico, Cf. Chervel (1990) e Gasparello (2002).

${ }_{9}^{9}$ Sobre a reforma Benjamin Constant, Cf. Cartolano (1994).
} 
seguiram as determinantes da reforma. O programa de ensino de 1898, por exemplo, dividiu o currículo do secundário em curso clássico (línguas e literaturas) e curso realista (ciências naturais).

A reforma aboliu os exames parcelados de preparatórios, pelos quais os estudantes não-matriculados em escola oficial obtinham certificados reconhecidos pela União, e introduziu o exame de madureza para verificar a cultura intelectual dos alunos e sua habilitação para os cursos superiores.

Mantendo o bacharelado em Ciências Sociais e Letras, com sete anos de curso, a reforma introduziu no $7^{\circ}$ ano a cadeira de História do Brasil, destacada da História Universal. O regulamento de 1892, assinado pelo ministro Fernando Lobo, estabeleceu a disciplina História do Brasil no $6^{\circ}$ e $7^{\circ}$ ano. O decreto de 1894, pelo ministro Cassiano do Nascimento, e o regulamento de 1897, por Amaro Cavalcante, mantiveram a disciplina História do Brasil no $6^{\circ}$ e $7^{\circ}$ ano.

O Código dos Institutos Oficiais de Ensino Superior e Secundário ${ }^{10}$, redigido no governo de Epitácio Pessoa, representou a exequibilidade da reforma Benjamin Constant. O código consolidou a estrutura seriada do ensino secundário, o exame de madureza e introduziu a matrícula por disciplina. Todavia, a implantação do curso seriado foi prorrogada por duas vezes e não se instalou durante a vigência da reforma.

O "Código Epitácio Pessoa" como ficou conhecido, privilegiou as disciplinas literárias em detrimento das científicas, estabeleceu o Regimento do Ginásio Nacional e consolidou o regime de equiparação. Porém, o ensino de História do Brasil como disciplina autônoma foi extinto, como se observa no programa de ensino de 1901. A autonomia foi restabelecida em 1915.

A reforma Rivadávia Corrêa, 1911, “[...] uma das mais ousadas e heterodoxas reformas da educação escolar no país" (CUNHA, 1980, p. 139), implantou a chamada "desoficialização" do ensino e revogou as medidas oficializadoras da reforma precedente (CURY, 2009). Introduziu o "ensino

\footnotetext{
10 Disponivel em:

<http://www6.senado.gov.br/legislacao/ListaPublicacoes.action?id=60451 >. Acesso em: 3 jun. 2010.
} 
livre" diversificado e flexível em estabelecimentos particulares, e o ensino secundário e superior como estruturas autônomas. A finalidade do secundário residia na formação do cidadão e não no ingresso no ensino superior. A reforma extinguiu a equiparação por meio de um curso secundário modelo e substituiu o "diploma" por "certificado" de frequência e aproveitamento. Também instituiu o exame de ingresso no ensino superior sem a obrigatoriedade do certificado de estudos secundários.

A reforma Carlos Maximiliano, 1915, buscou um meio-termo quanto à interferência do Estado na educação. Manteve o exame vestibular e acrescentou a exigência dos certificados de conclusão dos estudos secundários, obtidos por exames finais e de preparatórios. Além disso, restabeleceu o instituto de equiparação, reintegrando o Colégio Pedro II à função de estabelecimento modelo. A reforma restaurou os exames parcelados de preparatórios realizados ou em estabelecimentos oficiais ou particulares, e entre outros, incluiu a História do Brasil entre os doze preparatórios prestados em ginásio oficial.

Para Nagle (1976, p. 146), de 1890 a 1920 “o poder público se interessa apenas pela manutenção de estabelecimentos-padrão que sirvam de modelo para as demais escolas secundárias do País”, a União limita-se a conservar o Ginásio Nacional na Capital da República e “os Estados, assim mesmo nem todos, mantêm, em regra, apenas um ginásio-modelo nas suas capitais".

A iniciativa particular assume a responsabilidade pelo ensino secundário nesse período.

Tabela 3: Alunos matriculados em ginásios

\begin{tabular}{|c|c|c|}
\hline Ano & $\mathbf{1 9 1 8}$ & $\mathbf{1 9 2 5}$ \\
\hline Ginásios oficiais & 843 & 1.084 \\
\hline Ginásios particulares & 7.023 & 10.115 \\
\hline
\end{tabular}

Fonte: Bittencourt (1990, p. 35).

\section{Segunda conjuntura: 1920 A 1950}

Na década de 1920, o sistema político começou a dar sinais de exaustão, cujos sintomas eram evidentes na década anterior. A eclosão da Primeira 
Guerra forneceu elementos para difusão de ideias nacionalistas e a criação da Liga da Defesa Nacional (1916), Liga Nacionalista do Brasil (1917) juntamente com as ligas nacionalistas estaduais, a Liga pela Emancipação Feminina (1919), a Liga Pró-Saneamento, a Liga contra o Analfabetismo, dentre outras. $\mathrm{Na}$ ambiência nacionalista debatiam-se as reformulações da nação e do governo. (PANDOLFI, 2002).

O mandato presidencial de Artur Bernardes foi contestado inúmeras vezes: o movimento "tenentista", o levante do Forte de Copacabana (1922), a Revolta Paulista (1924) e a marcha da Coluna Prestes, a partir de 192511; a criação de partidos políticos de oposição, como, o Partido Democrático Nacional e o Partido Comunista do Brasil12.

A palavra de ordem era então "republicanizar a República". Para atingir a esse fim, a educação constituiu-se mais uma vez em locus privilegiado, instrumento central de criação de uma sociedade moderna ${ }^{13}$. No contexto de crise politica, sucederam-se as reformas estaduais do ensino primário e/ou normal empreendidas por Lourenço Filho no Ceará, 1922-1923, Francisco Campos em Minas Gerais, 1927-1929, Anísio Teixeira na Bahia, 1926, Fernando de Azevedo no Distrito Federal, 1927-1930, Anísio Teixeira, também no Distrito Federal, 1930-1935, entre outras.

O chamado movimento da Escola Nova surge nesse contexto, como uma das expressões do largo empenho em associar reforma da educação e reforma social. De outro, acreditava-se que a instrução pública ao superar os estreitos limites civico-nacionalistas serviria à reconstrução social e a regeneração moral. O movimento da Escola Nova desenvolveu-se a partir de inovações

\footnotetext{
${ }^{11}$ A formulação do tenentismo como categoria analítica é objeto de estudo de Borges (1992).

12 Para Decca (2006), os partidos políticos são novos elementos da política moderna e máquina de poder de arregimentação das massas, portanto, diferentes dos antigos partidos, órgãos de articulação de ideias na esfera do poder político do Estado nacional, porém, com pequena capacidade de recrutamento e adesão.

13 A frase "Essa não era a República dos meus sonhos" é do republicano Aristides Lobo. A expressão "republicanizar a República" também é utilizada por Motta (1992) ao analisar o centenário da Independência, dentre outros autores que investigam a década de 1920. Sobre a relação entre a "republicanização da República" e a educação, Cf., Gomes (2002) e Monarcha (1989).
} 
pedagógicas em modelos e experiências concretizadas na Europa e nos Estados Unidos da América do Norte.

Para Lourenço Filho, um dos representantes do movimento, a Escola Nova seria um conjunto de doutrinas e principios tendentes a rever as bases de aplicação da ciência à técnica educativa em consonância com o progresso das ciências biológicas e o espírito objetivo introduzido no estudo da ciência do homem. Segundo Monarcha (1989):

A Escola Nova, que, de início, nos coloca perante um projeto de reformulação pedagógica, aos poucos se revela como a emergência de uma nova pedagogia social, uma teoria de amplo alcance programático cujo objetivo era a construção do Homem Novo e da Boa Sociedade, articulando educação e democracia como estratégia de moralização das 'classes perigosas'. (MONARCHA, 1989, p. 17).

E completa:

Sobre o prisma da vanguarda pedagógica, Fernando de Azevedo, Francisco Campos, Antonio Carneiro Leão, entre outros, o tema da Escola Nova - a revisão dos métodos pedagógicos e finalidades sociais da educação - ensejava a oportunidade para tornar público um discurso científico sobre o povo e para o povo. (MONARCHA, 1989, p. 17, grifo no original).

Como parte das atividades em prol da educação popular e por iniciativa de Heitor Lira, foi fundada a Associação Brasileira de Educação (ABE) em 1924 no Rio de Janeiro. A ABE representou uma forma de institucionalizar a discussão concernente aos problemas da escolarização, e a ela, a instituição, associaram-se educadores, políticos, intelectuais e jornalistas. A associação realizou cursos, palestras, reuniões e conferências. A $3^{a}$ Conferência Nacional de Educação, por exemplo, promovida pela ABE em São Paulo em 1929, teve como tema geral o ensino secundário ${ }^{14}$.

Contrapondo-se aos objetivos estabelecidos para o secundário, ou seja, ensino humanista desprovido, portanto, de utilidade prática, intelectuais insistiam na tese de que tal modalidade de ensino não poderia mais contribuir

${ }^{14}$ Cf. Anais da III Conferência Nacional de Educação, 1929. 
"[...] para cimentar, na nossa classe superior, o desprezo pelas profissões práticas e utilitárias, saturando-a até hoje, da mania do funcionalismo". (CARNEIRO LEÃO, 1927, p. 4).

A reforma Rocha Vaz 15 estabelecida em 1925, estabeleceu a implantação generalizada de um ensino ginasial, seriado, com frequência obrigatória e ampliação das funções normativas e fiscalizadoras da União. Além do mais, extinguiu os exames de preparatórios e propôs "ensino secundário, como prolongamento do ensino primário, para fornecer a cultura média geral do País", mediante estudos com duração de seis anos e, segundo o Decreto n. 16.782-A, Art. 47, conferia o grau de bacharel em Ciências e Letras e exigia o certificado de aprovação no $5^{\circ}$ ano para admissão ao exame vestibular.

Até a derrogação da reforma em 1930, os programas de ensino para o secundário foram formulados pelos catedráticos do Colégio Pedro II e aprovados pela congregação da instituição. Os estabelecimentos particulares para obterem juntas examinadoras oficiais necessárias para autorização dos exames deveriam seguir esses programas.

Merece um parêntese a questão da qualidade do ensino e lucratividade das escolas particulares equiparadas. O depoimento de Vicente Licínio Cardoso em 1926 é elucidativo:

Gozavam os colégios equiparados do privilégio dos exames, o maior chamariz para os estudantes ávidos de atestados a baixo estudo, ainda que a alto preço. Ficariam virtualmente mortos na concorrência os que não fossem equiparados. Quem os queria, se não davam atestados de exames, se o estudo neles realizado obrigava aos exames oficiais? Caiu tanto o ensino que, apoiados exatamente nessa queda, começaram a surgir colégios particulares que anunciavam como reclame de sua capacidade de ensinar, o não serem equiparados. (CARDOSO, 1926 apud BASTOS SILVA, 1969, p. 267-268).

\footnotetext{
15 João Luiz Alves foi ministro da Justiça e Negócios Interiores e do Supremo Tribunal Federal. Rocha Vaz, foi professor da Faculdade de Medicina, e um dos membros do grupo que elaborou o anteprojeto do decreto federal além de dirigir a execução da reforma.
} 
O lucro com o ensino secundário representou empecilho na consecução da reforma Rocha Vaz. Além disso, as escolas particulares contavam com o apoio dos pais de alunos que "consideravam a escola seriada como um prolongamento desnecessário, adiando o ingresso dos filhos nas escolas superiores”. Para Bittencourt (1990, p. 45) a qualidade do ensino não era questionada porque "os pais podiam contar com as fraudes no decorrer dos exames, servindo-se de relacionamentos sociais e politicos”.

A reforma Rocha Vaz preparou a implantação definitiva do ensino secundário como curso regular. Nagle (1976) conclui que a principal mudança foi a introdução da seriação, entretanto, questões econômicas e de mentalidade dificultaram a efetivação do ensino secundário regular seriado. Caberia as reformas posteriores executadas por Francisco Campos e Gustavo Capanema a institucionalização do ensino secundário regular.

Com o Ministério da Educação e Saúde Pública, criado no governo provisório de Getúlio Vargas, Francisco Campos foi o primeiro titular, 19311934, e depois, Gustavo Capanema, 1934-1945. Ambos introduziram mudanças significativas no ensino secundário, instituindo um sistema educacional de nível nacional, ao contrário dos anos iniciais da República, onde os esforços foram direcionados para o ensino primário.

Os exames de admissão permaneceram com a reforma Francisco Campos, Decreto n. 19.890, de 18 de abril de 1931, capítulo III, que estendeu a equiparação aos colégios mantidos pelas municipalidades, associações e particulares.

A tabela abaixo demonstra a expansão do ensino secundário, 69\% para 209\%, entre 1930 e 1945.

Tabela 4: Matricula Escolar no Brasil de 1930 a 1945

\begin{tabular}{l|l|l}
\hline Ano & Primário & Secundário \\
\hline 1930 & 2.084 .000 & 83.000 \\
\hline 1935 & 2.413 .594 & 93.829 \\
\hline 1940 & 3.302 .830 & 170.057 \\
\hline 1945 & 3.496 .664 & 256.467 \\
\hline
\end{tabular}

Fonte: Hallewel (2005, p. 375). 
A reforma empreendida por Francisco Campos conferiu organicidade ao ensino secundário ao estabelecer currículo seriado, frequência obrigatória e diploma para ingresso no superior. Como afirma Castro (1955), a reforma foi significativa. Até então, predominava o sistema de "preparatórios" e exames parcelados (ROMANELLI, 1978; CUNHA, 1980). A partir de 1931 as normas administrativas e programáticas do ensino secundário foram centralizadas no Ministério da Educação e Saúde Pública.

Cabe lembrar os conflitos entre católicos e escolanovistas que influenciaram a implantação de tal reforma. Francisco Campos encontrou resistências e desconfianças por parte da Igreja Católica e para contorná-las permitiu a oferta do ensino religioso e estabeleceu o reconhecimento oficial para as escolas mantidas pelas municipalidades, associações e particulares. (RESNIK, 1992).

O sucesso da reforma se deve ao fato de Francisco Campos ter encontrado alicerces mais sólidos além do apoio da opinião pública e projetos mais consensuais, resultantes de debates e inquéritos.

O ensino secundário ficou organizado em dois ciclos: curso fundamental ou ginasial, com duração de cinco anos, e curso complementar, dois anos (DALABRIDA, 2009). Quanto aos programas de ensino, a reforma estabeleceu os programas dos cursos e suas instruções metodológicas. Findava o monopólio do Colégio Pedro II e demais instituições no tocante à formulação de programas.

Para Hollanda (1957), as instruções metodológicas agregadas aos programas de ensino constituíram o aspecto mais positivo da reforma e objetivavam renovar métodos didáticos. O programa de ensino, denso e detalhado, previa a carga horária semanal para as disciplinas.

A reforma previa ainda uma Faculdade de Educação, Ciências e Letras que chegou a ser criada pela legislação. Todavia a formação do magistério para o secundário, e nela a formação de professores para o ensino de História, seria 
concretizado pelas universidades de São Paulo, 1934, e do Distrito Federal, $1935^{16}$.

A demanda de professores para o magistério secundário era maior do que a oferta de ensino superior e a proporção dos licenciados era inferior a $20 \%$ da demanda. Em 1936, por exemplo, apenas oito alunos foram graduados em História e Geografia na primeira turma da Universidade de São Paulo (USP) ${ }^{17}$.

Entre os chamados "intérpretes do Brasil" Gilberto Freyre e Sérgio Buarque de Holanda representam os nomes de destaque da historiografia brasileira. Na opinião de Sena (2003, p. 78) esses autores "se propuseram a escrever uma história social do Brasil procurando no passado, em nossas relações específicas com a tradição ibérica, o sentido do Brasil contemporâneo".

Sérgio Buarque de Holanda lecionou História da América e Cultura Luso-Brasileira na Faculdade de Filosofia da Universidade do Distrito Federal, e História do Brasil na Faculdade de Filosofia da USP. Influenciado por Max Weber, Marc Bloch e Lucien Febvre, trouxe da estada na Alemanha reflexões conceituais inovadoras sobre a formação social brasileira (DIAS, 1988), como se pode ler em Raizes do Brasil, publicado pela primeira vez em 1936.

Gilberto Freyre, com Casa-grande \& Senzala, publicada em 1933, divulgou a tese da "democracia racial" no Brasil, para tanto, fundamentou-se nas teorias culturalistas de Franz Boas, para quem os povos diferenciavamse entre si, não por traços físicos, mas por aspectos culturais.

Ao prefaciar Casa-Grande \& Senzala, Antônio Cândido (1967, p. XI) considerou que esse livro, ao lado de Raizes do Brasil de Buarque de Holanda e Formação do Brasil contemporâneo de Caio Prado Júnior, formavam um conjunto de livros "que podemos considerar chaves, os que parecem exprimir a mentalidade ligada ao sopro de radicalismo intelectual e análise social que eclodiu depois da Revolução de 1930”.

\footnotetext{
${ }^{16}$ Cf. Nagle (1976) e Lacombe (1973).

${ }^{17}$ Dados do Arquivo da Seção de Alunos da Faculdade de Filosofia, Letras e Ciências Humanas da USP, Cf., Bittencourt (1990).
} 
À frente do Ministério da Educação e Saúde Pública, Gustavo Capanema organiza o Plano Nacional de Educação previsto na Constituição de 1934. Os avanços constitucionais relativos à educação decorriam do reconhecimento da educação como direito também dos adultos, seguiu-se então à criação do Conselho Nacional de Educação, a elaboração do Plano Nacional de Educação e a vinculação constitucional de recursos, a União e os Estados deveriam aplicar $10 \%$ e $20 \%$ de seus impostos, respectivamente, em educação. (HORTA, 2000).

Tais iniciativas soaram como um golpe no poder dos localismos. Gustavo Capanema encaminhou suas iniciativas em consonância com as diretrizes nacionalistas, autoritárias e centralizadoras do Estado Novo. Foi nesse contexto que surgiu a Lei Orgânica do Ensino Secundário, em 1942. Entre outros, ficou estabelecido que os programas de ensino fossem livres, claros e flexíveis, indicando tão-somente o sumário e as diretrizes da disciplina. Os conteúdos eram dispostos em "unidades temáticas", todavia, note-se, a prática das "unidades" encontrou obstáculos frente à tradição de conteúdos isolados.

A Lei Orgânica do Ensino Secundário era contrária a coeducação e recomendava estabelecimentos de exclusiva frequência feminina, para as alunas, havia educação física com horário reduzido e o ensino de economia doméstica. Por questões econômicas a educação em separado amenizou nas disposições posteriores.

Com duração de sete anos, o secundário comportava curso ginasial, quatro anos, e colegial, com três, organizado em clássico e científico.

As disciplinas históricas foram objeto de revisão em 1951, quando se aprovaram novos programas: "No decurso do período de "adaptação" ao curso ginasial e aos cursos clássico e científico, determinava-se que os professores orientariam as suas lições, de modo que os livros didáticos, então em uso, pudessem ser utilizados". (HOLLANDA, 1957, p. 48-49). 


\section{A disciplina História do Brasil nos programas de ensino secundário (1889-1950)}

O presente tópico apresenta as idas e vindas da disciplina História do Brasil nos programas curriculares nacionais, em diálogo com as disciplinas de História Geral/Universal e História da América. Nota-se, que a História como disciplina ganha maior extensão a partir dos programas de ensino de 1931.

Desde a fundação do Colégio Pedro II os estudos históricos integraram os planos de estudos da instituição. A cadeira de História do Brasil foi estabelecida "Por ordem do Imperador", em 3 de abril de 1849. Como afirmou Doria (1997, p. 69), o Decreto de 25 de março de 1849, "decreto Monte Alegre", "dividia a cadeira de História e Geografia. A 3 de abril o Ministro Monte Alegre comunicou à reitoria do Colégio ter Sua Majestade o Imperador havido a bem da $1^{\text {a }}$ cadeira de História e Geografia, desligar o ensino da História do Brasil”.

A disciplina História do Brasil foi lecionada por Antonio Gonçalves Dias, como afirmou Doria (1997, p. 69): "Distribuído o ensino de História e Geografia no Colégio, lecionaria Calógeras a $1^{\text {a }}$ cadeira, Macedo a segunda, a História Pátria a cargo de Gonçalves Dias”. Coube a Joaquim Manuel de Macedo ser designado titular da cadeira em caráter permanente. Posteriormente, esse autor será celebrado como o primeiro historiador do colégio, e o primeiro a publicar um livro didático de História do Brasil.

Os demais professores foram: Antônio Gonçalves Dias, Barão do Rio Branco, Justiniano José da Rocha, Frei Camilo de Monserrate, Barão Homem de Melo, Moreira de Azevedo e João Ribeiro. (LACOMBE, 1973).

Cinco décadas depois História do Brasil seria integrada na cadeira de História Universal: "Desaparecia em 1901 a cadeira inaugurada por Joaquim Manuel de Macedo e ocupada na época por Capistrano de Abreu no Externado e Mattoso Maia no Internato” (Idem, p. 181). Em sinal de protesto, Capistrano de Abreu negou-se a lecionar a disciplina por ser "apêndice" da História Universal.

A trajetória da disciplina História do Brasil nos programas de ensino caracterizou-se ora pela integração, ora pela autonomia frente à História 
Universal. De início, História do Brasil era ensinada juntamente com Geografia e a História Universal, em 1855 estabeleceu-se a autonomia disciplinar.

No programa de 1856 a História do Brasil, denominada História Pátria, era ensinada no $4^{\circ}$ ano do curso secundário. Nos programas de 1858, 1862, 1878, 1882 e 1895, em conjunto com a Geografia do Brasil sob a denominação “Corografia e História do Brasil". Os programas de 1877, 1892 e 1893, ao contrário, estipulam o ensino de História do Brasil na $7^{a}$ série, separadamente da disciplina Corografia do Brasil.

O programa de ensino de 1898 organizava o currículo do secundário em "curso clássico" com línguas e literaturas e "curso realista" com ênfase em ciências. Então, a cadeira de História do Brasil constava no $6^{\circ}$ ano do curso realista e no $7^{\circ}$ do curso clássico.

O programa de 1901 fez constar História do Brasil como parte da História Universal. Tratava-se, segundo Gasparello (2002), de uma adaptação do modelo francês estabelecido em 1880 pelo Ministro da Instrução Pública Jules Ferry, em que a história escolar constituía um curso completo de História Universal com vistas à compreensão da história da nação.

No programa de ensino de 1912, História do Brasil não constava como disciplina autônoma nas seis séries do secundário, seu conteúdo estava integrado na disciplina História Universal ministrada na $6^{\mathrm{a}}$ série. O programa de 1915 introduzia História do Brasil como disciplina autônoma no $5^{\circ}$ e no último ano de curso. Nos programas de 1926 e 1929, este o último formulado pelos catedráticos do Colégio Pedro II, ministrava-se a disciplina na $5^{\mathrm{a}}$ série.

A reforma do ensino secundário de 1931 restabeleceu a História da Civilização integrada a História Geral e História do Brasil e da América. Em Como se ensina História, 1935, Jonathas Serrano concluiu pela inexequibilidade do ensino de História da Civilização, uma vez que o número de pontos aumentara e o número de aulas diminuíra; e ainda, que "o título de alguns pontos é pouco feliz" [...] "se os autores de reformas e programas fossem obrigados a lecionar, sentiriam melhor a inexequibilidade de certas exigências teóricas, sem fundamento na experiência” (SERRANO, 1935, p. 28- 
29). A medida gerou debates sobre o ensino de História, neles, os debates, afloravam concepções inclusive sobre a sociedade a ser reconstruída.

O tema do universalismo era um dos destaques nos meios educacionais brasileiros e internacionais. O tema estava em correspondência com o movimento internacional pela paz mundial iniciado após a $1^{\mathrm{a}}$ Guerra, em substituição ao espírito nacionalista avaliado como agressivo e belicoso.

Exemplo desse movimento são os eventos em capitais sul-americanas: Congresso Científico Pan-americano, Lima, 1924, Congresso Universitário Sul-Americano, Montevidéu 1931, $7^{\text {a }}$ Conferência Pan-americana, Montevidéu, 1933, Conferência Interamericana de Consolidação da Paz, Buenos Aires, 1936, $2^{\circ}$ Congresso Internacional de História da América, Buenos Aires, 1937, e $2^{\text {a }}$ Conferência Americana de Comissões Nacionais de Cooperação Intelectual, Havana, 1941.

Atribuía-se à educação escolar papel decisivo na formação de mentalidades pacifistas e universalistas. É aí que o ensino de História e seus livros didáticos recebem interferência de comissões internacionais criadas para a consecução de tal finalidade. Surgia um clima propício à rediscussão e reavaliação dos estereótipos nacionalistas depreciadores da imagem de certas nações ${ }^{18}$.

O Instituto Histórico e Geográfico Brasileiro (IBHE) participou dos debates, recebeu e expediu notificações e serviu de reação à perspectiva universalista. Em 1934, Max Fleiuss, secretário-geral do IHGB, expôs em memorial as razões para a inclusão da História do Brasil no curso secundário, alegava que a exclusão poderia “originar um povo órfão de caráter".

A. F. Cesarino Jr, membro do IHGB, profere palestra nesta instituição em defesa da reinclusão da cadeira de História Pátria para cimentar a unidade cultural da população brasileira. Wanderley Pinho, também membro do IHGB e deputado federal, apresentou projeto para manutenção da cadeira de História do Brasil na $5^{\mathrm{a}}$ série do secundário, alegando que o conhecimento do

\footnotetext{
18 Para Leite (1969) a análise dos livros didáticos a cargo da UNESCO verificou que o defeito da maioria dos livros didáticos residia na tendência a monopolizar as virtudes de um país e atribuir a responsabilidade dos conflitos e retrocessos aos inimigos da nacionalidade. Em 1933 o Brasil firmou convênio com a Argentina para revisão dos textos de História e Geografia, como resultado criaram-se comissões revisoras dos didáticos em ambos os países.
} 
passado e da tradição possibilitaria a (re) criação do orgulho nacional e do sentimento patriótico. Além de Wanderley Pinho, outros deputados oposicionistas, Levy Carneiro e Pedro Calmon, defenderam o restabelecimento da disciplina História do Brasil, todavia o projeto foi arquivado. O debate retornaria por ocasião do Plano Nacional de Educação. (RESNIK, 1992; LACOMBE, 1973).

De fato, nessa ocasião debateu-se a necessidade de estabelecer o que deveria ser ensinado e quais os programas melhor atenderiam os objetivos do ensino secundário. Nessa mesma ocasião, evidenciaram-se divergências entre a Associação Brasileira de Educação, a instituição posicionava-se a favor dos estudos modernos e científicos, e o Centro Dom Vital, instituição representativa da ala católica e a favor das humanidades clássicas.

Jonathas Serrano, relator da comissão do ensino secundário do Conselho Nacional de Educação (CNE), pertencia à ala católica e defendia o retorno da História Pátria. Basílio de Magalhães, relator da resposta do IHGB ao Inquérito de Capanema ${ }^{19}$, posicionava-se a favor do retorno da disciplina História do Brasil e do currículo de orientação científica introduzido por Francisco Campos. O currículo aprovado pelo CNE expressou tendência conservadora ou pró-clássica.

A votação do Plano Nacional de Educação (PNE) foi interrompida pelo "golpe de 1937". O caráter conservador do PNE aprovado pelo CNE ganhou força com o Estado Novo mostrando-se fundamental nas campanhas em prol do ensino de História do Brasil. Os apelos a "Pátria" e ao "patriotismo", apelos centrais no discurso estadonovista, contribuíram para redirecionar o ensino de História.

À formação do sentimento patriótico aliava-se a repressão aos comunistas. Para Resnik (1992, p. 114): "O ideal cívico-patriótico tem agora, ao nível discursivo, um interlocutor forjado: o comunismo - empecilho à paz

19 Em janeiro de 1936, Gustavo Capanema enviou um questionário para diversas instituições, órgãos e personalidades. O questionário objetivava recolher dados de opinião para um inquérito educacional elaborado por educadores com o intuito de confluir a atenção de diversos segmentos da sociedade em torno da elaboração de um plano integral e nacional para a educação. 
mundial”. A polarização entre História do Brasil com sentido nacionalista e História da Civilização com sentido universalista acentuou-se.

Várias campanhas foram realizadas pelo IHGB, Colégio Militar do Rio de Janeiro e Correio da Manhã sobre a importância da História do Brasil no ensino secundário. Em abril de 1939, Gustavo Capanema expede a Portaria Ministerial n. 142 determinando a separação de aulas de História do Brasil no curso secundário fundamental e na $1^{\text {a }}$ série do complementar. Determinava ainda que as provas de História da Civilização contivessem pelo menos uma questão sobre História do Brasil. (LACOMBE, 1973).

Em edição de 1940 o Correio da Manhã alardeava que os patriotas de fato conheciam e praticavam as normas da "boa moral", isso porque estudavam o passado nacional e conheciam as grandezas e virtudes da história da pátria: o heroísmo dos descobridores e bandeirantes, a bravura na expulsão dos invasores, os movimentos libertadores, o humanismo da cruzada abolicionista e a vocação pacífica e hospitaleira do povo. (RESNIK, 1992, p. 111).

A campanha do Correio da Manhã encerrou-se com a Portaria de 19-031940, expedida por Gustavo Capanema: “A partir do ano escolar de 1940, a História do Brasil passará a constituir uma disciplina autônoma da História Universal, no curso fundamental do ensino secundário" (Idem). A partir de então foi ministrada nas $4^{\mathrm{a}}$ e $5^{\mathrm{a}}$ séries paralelamente à História Geral e História da América.

Em 1943 os programas de ensino de História do Brasil para as $3^{a}$ e $4^{a}$ séries do curso ginasial vieram à luz. Em 1945 o programa de História do Brasil para o $3^{\circ}$ ano do curso colegial, integrados à matriz comum dos cursos clássico e científico.

Seja como for, a Lei Orgânica do Ensino Secundário reforçou as bases de um currículo de sentido patriótico e a preocupação moral. Os programas de História foram elaborados por Jonathas Serrano e Delgado de Carvalho, os resultados deixaram entrever diferenças significativas, de um lado uma história "tradicional", de outro, uma história "renovadora". Com efeito, Jonathas Serrano propôs um programa centrado nos eventos políticos, ao 
enfatizar a formação da consciência patriótica e reverenciar as tradições religiosas. Delgado de Carvalho secularizava os eventos despindo-os de exaltação. Para Resnik (1992), o programa de ensino aproximou-se das concepções de Jonathas Serrano.

Em suma: as informações a respeito dos programas de ensino para a disciplina História do Brasil permitem concluir que a seriação sofreu alterações profundas entre 1889 e 1950. Entre 1889 a 1930 a disciplina constou em uma das séries do secundário. Entre 1931 e 1950, último ano em que vigorou o programa da reforma Capanema, a disciplina foi ministrada em pelo menos duas séries.

\section{Quadro 1 - Seriação da disciplina História do Brasil: 1889-1950}

\begin{tabular}{|l|l|l|}
\hline \multicolumn{1}{|c|}{ Programa } & \multicolumn{1}{c|}{ Disciplina } & \multicolumn{1}{c|}{ Séries } \\
\hline Programa de 1892 & História do Brasil & $7^{\circ}$ ano \\
\hline Programa de 1893 & História do Brasil & $7^{\circ}$ ano \\
\hline Programa de 1895 & $\begin{array}{l}\text { História e Corografia do } \\
\text { Brasil }\end{array}$ & $7^{\circ}$ ano \\
\hline Programa de 1898 & História do Brasil & $\begin{array}{l}6^{\circ} \text { ano do Curso Realista } \\
7^{\circ} \text { ano do Curso Clássico }\end{array}$ \\
\hline Programa de 1901 & História Universal & \multicolumn{1}{c|}{} \\
\hline Programa de 1912 & História Universal & $6^{\circ}$ série (4 horas) \\
\hline Programa de 1915 & História do Brasil & $5^{\circ}$ ano (4 horas) \\
\hline Programa de 1926 & História do Brasil & $5^{\circ}$ ano (80 Lições) \\
\hline Programa de 1929 & História do Brasil & $5^{\circ}$ ano (80 Lições) \\
\hline Programa de 1931 & $\begin{array}{l}\text { História da América e do } \\
\text { Brasil }\end{array}$ & $\begin{array}{l}3^{\mathrm{a}}, 4^{\mathrm{a}} \text { e } 5^{\mathrm{a}} \text { séries(2 h } \\
\text { semanais) }\end{array}$ \\
\hline Portaria 1940 & História do Brasil & $4^{\mathrm{a}}$ e $5^{\mathrm{a}}$ séries \\
\hline Programa de 1943 & História do Brasil & $3^{\mathrm{a}}$ e $4^{\mathrm{a}}$ séries ginásio \\
\hline Programa de 1945 & História do Brasil & $\begin{array}{l}3^{\mathrm{a}} \text { série do colegial (clássico } \\
\text { e científico) }\end{array}$ \\
\hline
\end{tabular}

Fonte: Programas de ensino de 1889 a 1950.

Quanto à inclusão da disciplina História no secundário, sem fazer distinção entre História Geral e do Brasil, em 1930 constava em três das cinco séries do secundário.

A partir de 1931, foi incluída em todas as séries do curso fundamental e $1^{\text {a }}$ série do complementar pré-jurídico. Em 1943 integrou o currículo das sete séries do ensino secundário. 
Em 1931, História do Brasil foi integrada em três séries; em 1940 integrada em duas séries ginasiais, e em 1942, em duas séries ginasiais e uma no colegial.

Em 1931 os conteúdos da disciplina foram englobados a História da América, denominada História da América e do Brasil, e ensinados em três séries, em paralelo ensinava História Geral: Antiga, Média, Moderna e Contemporânea.

Em 1943 os conteúdos de História do Brasil foram subdivididos em Período Colonial: “1. Do Descobrimento até a Independência”, e Independente: “2. Do Primeiro Reinado até o Estado Novo”.

A disciplina recebeu maior extensão a partir de 1931 quando comparada aos currículos anteriores. Bittencourt (1990, p. 61) fez uma ressalva ao afirmar que a História não era, antes de 1931, conteúdo transmitido com exclusividade apenas pela disciplina História. Esse conhecimento era difundido por outras "matérias" escolares, por exemplo, escreve a autora, "a Antiguidade foi tema de estudos nas diversas disciplinas literárias e de religião".

\section{Considerações finais}

O presente artigo evidenciou as mudanças pelas quais passaram o ensino secundário no Brasil desde a proclamação da República até a primeira metade do século XX e as relações de poder em disputa na elaboração e consolidação do currículo de História da Brasil nas séries que compunham o nível secundário de ensino.

Apesar da fronteira entre as duas distintas conjunturas politicas e culturais na primeira metade do século XX acontecer, conforme Lorenzo e Costa (1997), Sandes (2000), dentre outros, nos anos 1920, ao analisar a trajetória da disciplina História do Brasil nesse mesmo período, pode-se determinar, de acordo com Bittencourt (1990, p. 61) e outros, que a disciplina ganhou maior ênfase na década de 1930, a partir da Reforma Francisco Campos (1931). 
As mudanças na distribuição dos conteúdos e na seriação da disciplina História do Brasil no curso secundário, a partir do programa de ensino de 1931, contribuíram para a expansão da indústria livreira. Tal expansão contribuiu para o aperfeiçoamento da indústria gráfica no Brasil e consequente modificação das características materiais das edições escolares no que se refere à aparência, resistência do livro e disposição do conteúdo, tema para um novo artigo.

\section{Referências}

ARRUDA, J. J.; TENGARRINHA, J. M. Historiografia luso-brasileira contemporânea. Bauru, SP: EDUSC, 1999.

BASTOS SILVA, G. A educação secundária: perspectiva histórica e teoria. São Paulo, SP: Nacional, 1969.

BITTENCOURT, C. M. F. Pátria, civilização e trabalho. São Paulo, SP: Loyola, 1990.

CARNEIRO LEÃO, A. A instrução secundária. Revista Escolar, São Paulo, v. 3, n. 28, abr. de 1927.

CARVALHO, J. M. de. Os bestializados. Rio de Janeiro e a República que não foi. São Paulo, SP: Companhia das Letras, 1987.

A formação das almas: imaginário da República no Brasil. São Paulo, SP: Companhia das Letras, 1990.

CARTOLANO, M. T. P. Benjamin Constant e a instrução pública no início da República. Campinas, 1994. Tese (Doutorado em Educação) - Faculdade de Educação - Universidade Estadual de Campinas, 1994.

CASALECCHI J. Ê. O Partido republicano paulista: politica e poder (18891926). São Paulo, SP: Brasiliense, 1987.

CASTRO, A. D de. A história no curso secundário brasileiro. Revista de Pedagogia, São Paulo, 1, p.57-78, jan./jun., 1955.

CHERVEL, A. História das Disciplinas Escolares: reflexões sobre um campo de pesquisa. Teoria \& Educação, Porto Alegre, n. 2, p. 177-229, 1990.

Quando surgiu o ensino "secundário?”. Revista da Faculdade de Educação, 18, 1, p. 99-112, jan./-jun. 1992. 
CHERVEL, A.; COMPĖRE, M-M. As humanidades no ensino. Educação e Pesquisa, São Paulo, v. n. 25, 149-170, jul./-dez. 1999.

CUNHA, L. A. Educação e desenvolvimento social no Brasil. Rio de Janeiro, RJ: Francisco Alves, 1980.

CURY, C. R. J. A desoficialização do ensino no Brasil: a reforma Rivadávia. Educação e Sociedade, Campinas, v. 30, n. 108, p. 717-738, out. 2009.

DALABRIDA, N. A reforma Francisco Campos e a modernização nacionalizada do ensino secundário. Educação, Porto Alegre, v. 32, n. 2, p. 185-191, maio/ago., 2009.

DIAS, M. O. da S. Estilo e método na obra de Sérgio Buarque de Holanda. In: NOGUEIRA, A. R.; PACHECO, F. de M.; PILNIK, M.; HORCH, R. É. Sérgio Buarque de Holanda: vida e obra. São Paulo, SP: Secretaria do Estado da Cultura/Arquivo do Estado/USP/Instituto de Estudos Brasileiros, 1988.

DORIA, E. Memória-Histórica do Colégio Pedro II: 1837-1937. 2. ed. Brasília, DF: INEP, 1997.

GASPARELLO, A. Construtores de identidades: os compêndios de História do Brasil do Colégio Pedro II (1838-1920). São Paulo, 2002. Tese (Doutorado em Educação). Pontifícia Universidade Católica de São Paulo, São Paulo, 2002.

GOMES, A. de C. A escola republicana: entre luzes e sombras. In: GOMES, A. de C.; PANDOLFI, D. C.; e ALBERTI, V. (Org.). A República no Brasil. Rio de Janeiro, RJ: Nova Fronteira: CPDOC, 2002, p. 384-450.

História e historiadores. 2. ed. Rio de Janeiro, RJ: Ed. FGV, 1999.

HAIDAR, M. de L. M. O ensino secundário no Brasil império. 2. ed. São Paulo, SP: EDUSP, 2008.

HALLEWELL, L. O livro no Brasil: sua história. 2. ed. São Paulo, SP: Edusp, 2005.

HOLLANDA, G. de. Um quarto de século de programas e compêndios de História para o ensino secundário brasileiro (1931-1956). Rio de Janeiro, RJ: INEP/CBPE, 1957.

HORTA, J. S. B. A I Conferência Nacional de Educação ou de como monologar sobre educação na presença de educadores. In: GOMES, A. C. (Org.). Capanema: o ministro e seu ministério. Rio de Janeiro, RJ: FGV/USF, 2000. p. 143-172.

LACOMBE, A. J. Introdução ao estudo da História do Brasil. São Paulo, SP: Nacional-EDUSP, 1973. 
LEITE, M. L. M. O ensino da História no primário e no ginásio. São Paulo, SP: Cultrix, 1969.

LORENZO, H. C. de, e COSTA, W. P. da. (Org.) A década de 1920 e as origens do Brasil moderno. São Paulo, SP: Ed. UNESP, 1997.

MONARCHA, C. A reinvenção da cidade e da multidão; dimensões da modernidade brasileira: a Escola Nova. São Paulo, SP: Cortez, 1989.

NAGLE, Jorge. Educação e Sociedade na Primeira República. São Paulo, SP: EPU; Rio de Janeiro, RJ: Fundação Nacional de Material Escolar, 1976.

OLIVEIRA, L. L. Cultura e identidade nacional no Brasil do século XX. In GOMES, A. de C.; PANDOLFI, D. C.; ALBERTI, V. (Org.). A república no Brasil. Rio de Janeiro, RJ: Nova Fronteira- CPDOC, 2002, p. 338-383.

PANDOLFI, D. C. Voto e participação política nas diversas repúblicas do Brasil. In: GOMES, A. de C.; PANDOLFI, D. C.; e ALBERTI, V. (Org.). A república no Brasil. Rio de Janeiro, RJ: Nova Fronteira- CPDOC, 2002, p. 64115.

REIS, J. C. As Identidades do Brasil de Varnhagen a FHC. Rio de Janeiro, RJ: Editora Fundação Getúlio Vargas, 1999.

RODRIGUES, J. H. História e historiadores do Brasil. São Paulo, SP: Fulgor, 1965.

Prefácio. In: ABREU, Capistrano de. Capítulos de história colonial (1500-1800). 7. ed. Belo Horizonte: Itatiaia; São Paulo, SP: Publifolha, 2000.

RESNIK, L. Tecendo o amanhã (a história do Brasil no ensino secundário): programas e livros didáticos. (1931-1945). Rio de Janeiro, 1992. Dissertação (Mestrado em História) - Universidade Federal Fluminense, Rio de Janeiro, 1992.

ROMANELli, O. História da educação do Brasil. 5. ed. Petrópolis, RJ: Vozes, 1978.

SANDES, N. F., A invenção da Nação, entre a Monarquia e a República. Goiânia, GO: Ed. UFG, 2000.

SENA, C. Interpretações dualistas do Brasil. Goiânia, GO: Editora UFG, 2003.

SERRANO, J. Como se ensina História. São Paulo, SP: Melhoramentos, 1935. 
VIANNA, H. Ensaio biográfico. In: ABREU, Capistrano de. O descobrimento do Brasil. São Paulo, SP: Martins Fontes, 1999.

WEHLING, A. A Invenção da História. Rio de Janeiro, RJ: Niterói: Gama Filho/UFF, 1994.

Recebido: 13 de agosto de 2017

Aceito: 10 de setembro de 2017

Publicado: 19 de setembro de 2017 